\title{
Age-related differences in glycaemic control in diabetes
}

\author{
Elizabeth Selvin • Christina M. Parrinello
}

Received: 13 September 2013 / Accepted: 16 September 2013 / Published online: 5 October 2013

(C) Springer-Verlag Berlin Heidelberg 2013

Keywords Diabetes in the elderly · Epidemiology Glycaemic control $\cdot$ Glycated haemoglobin $\cdot \mathrm{HbA}_{1 \mathrm{c}} \cdot$ National survey $\cdot$ Survival bias

\section{Abbreviation \\ NHANES National Health and Nutrition Examination Survey}

There has been a dramatic increase in the global burden of type 2 diabetes over the past three decades [1]. In addition to obesity, age is one of the most important risk factors for type 2 diabetes and the burden of the disease is very high in older age groups. Among adults in the USA aged 65 or older, the prevalence of diagnosed diabetes in 2011 was $20 \%$, or more than eight times higher than the prevalence among adults 18 to 44 years of age (2.4\% prevalence) [2]. The strong association of diabetes with age is of particular concern given the global ageing of the population [3]. Nevertheless, the incidence and prevalence of type 2 diabetes is also increasing among young persons $[1,4-6]$.

The article by Berkowitz et al [7] in this issue of Diabetologia examins whether younger age at diabetes diagnosis is associated with worse glycaemic control. They analysed data from the 2005-2010 National Health and Nutrition Examination Survey (NHANES), a nationally representative sample of the civilian non-institutionalised population of the USA. The authors concluded that persons diagnosed with diabetes between the ages of 30 and 65 years had worse glycaemic control than those diagnosed at 65 years of

E. Selvin $(\bowtie) \cdot$ C. M. Parrinello

Department of Epidemiology and the Welch Center for Prevention, Epidemiology and Clinical Research, Johns Hopkins Bloomberg School of Public Health, 2024 E. Monument Street, Suite 2-600, Baltimore, MD 21287, USA

e-mail: 1selvin@jhsph.edu age or older. This raises an important question: why might younger people have inferior glycaemic control compared with their older counterparts?

Berkowitz et al found that the use of insulin was much higher and treatment with sulfonylurea medications much lower among individuals with a younger age at diagnosis. In addition, even though people diagnosed with diabetes younger than 65 had inferior glycaemic control, they had fewer comorbid conditions, such as end stage renal disease, congestive heart failure and chronic obstructive pulmonary disease. Persons with younger-onset diabetes were also more likely to be obese, to be ethnically either Hispanic or nonHispanic black, and to have a longer duration of diabetes. It is important to note that, in this study, the diagnosis of diabetes, medication use and comorbid conditions were all selfreported. A concern is that there are age-related differences in screening and diagnostic practices. Indeed, older age is explicitly incorporated into some diabetes screening recommendations; for example, the American Diabetes Association and Diabetes UK both recommend that, in the absence of major risk factors, routine screening for diabetes should begin in middle-age $[8,9]$. It is unclear to what degree possible detection bias may have influenced the observed results. Furthermore, as the authors acknowledge, certain segments of the US population were not included in NHANES, such as people residing in nursing homes or long-term care facilities. The current national prevalence of diabetes among residents of nursing homes and long-term care facilities is unknown but is undoubtedly high [10].

Diabetes is progressive and glucose levels are known to increase with age $[8,11]$. However, there is also evidence for differences in the pathophysiology of type 2 diabetes in older compared with younger individuals. It is unclear to what degree diabetes in the elderly may primarily result from an age-related decline in beta cell function. It has been hypothesised that impaired insulin secretion, rather than insulin resistance, commonly leads to diabetes in elderly adults 
compared with their younger counterparts $[12,13]$. This may, in part, explain the relative lack of effectiveness of metformin therapy (which decreases hepatic glucose output and increases insulin action) in older participants in the landmark Diabetes Prevention Program (DPP) Trial [14, 15]. Persons diagnosed with type 2 diabetes at younger ages may have a more severe form of the disease, associated with a higher degree of insulin resistance, more rapidly increasing glucose levels, and worse glycaemic control that is more resistant to current treatment modalities [16].

Survival bias is also a critical issue in the interpretation of age-related effects in any cross-sectional study. People who are ill-including the most severe, complicated and/or uncontrolled cases of diabetes - are more likely to die at a younger age compared with individuals with late-onset and/or wellcontrolled diabetes. By definition, these persons will be underrepresented in a large, population-based survey. Prospective follow-up of individuals over time does not resolve this issue entirely, since differential entry into the study and/or loss to follow-up can lead to survival bias in prospective cohort studies. Previous studies have reported a slowing of diabetes incidence with age [17]. It is possible that some (or all) of this plateau is attributable to higher rates of study dropout among persons with newly developed disease.

To address survival bias in their report, Berkowitz et al controlled for duration of diabetes. The authors also conducted several sensitivity analyses. First, they restricted analyses to persons older than 70 years of age, to increase the representation of people who had had diabetes for a significant amount of time, particularly among those diagnosed at a younger age. In a second analysis, they included only those persons who had had diabetes for fewer than 5 years, since it is unlikely that death within 5 years of diagnosis would be due to diabetes, thus limiting the potential for survival bias to arise. In a third analysis, they restricted analyses to people taking insulin, to limit the study population to those with more severe diabetes.

Unfortunately, these analytical approaches cannot fully overcome the possible profound selection and survival issues. Adjustment for duration of diabetes may actually exacerbate the survival bias effect. This adjustment necessarily invokes a comparison between an older and younger cohort: a person who has had diabetes for 10 years but was diagnosed with diabetes at under 65 years of age will be younger than a person who has had diabetes for 10 years but was diagnosed at an age above 65 years. In the USA, life expectancy is approximately 78 years and, inevitably, those who live longer are generally healthier. Thus, the older group (who developed diabetes later in life) may have better general health than the younger group, having survived to a more advanced age.

So where do we go from here? Berkowitz et colleagues' concluding points about individualisation of treatment and the need for prospective studies are good ones. Most of our current evidence in the field of type 2 diabetes comes from studies of middle-aged adults. Diabetes in older individuals is often complicated by comorbid conditions, frailty, multiple medications, frequent hypoglycaemia and cognitive or functional impairment. Thus, older people with diabetes are commonly excluded from clinical trials and epidemiological studies. Consequently, we have limited understanding of the incidence and natural progression of diabetes and the best approaches to treatment in older people. Compounding these knowledge gaps is the fact that randomised clinical trials have shown little benefit of (and perhaps even harm caused by) very intensive glycaemic control in the risk of macrovascular outcomes [18-22]. There is controversy regarding whether a focus on very tight glycaemic control results in overall benefit in type 2 diabetes, particularly among the elderly and those with long-standing disease [8, 23, 24].

At the other end of the age spectrum, the increase in overweight and obesity in young people in many countries has been dramatic. In the 1970 s in the USA, only about $5 \%$ of children were overweight or obese. Now, the prevalence is almost 20\% [5,6]. Consequently, type 2 diabetes among children and adolescents-once a rare condition-is now more common than type 1 diabetes in some subgroups of the population [4, 25, 26]. Unfortunately, little is known about this expanding population, particularly in relation to best approaches to treatment. Results of a recent clinical trial showed that adolescents with type 2 diabetes may respond to treatment differently from adults: young people with type 2 diabetes may not respond as well to monotherapy and may be more likely to need combination or insulin therapy to achieve glycaemic control [27]. An additional sobering trend is the growing prevalence of pre-diabetes in youth [28-30]. The best approach to the prevention of diabetes and complications in these high-risk young people is uncertain [31].

Ultimately, in light of these many uncertainties, we think it is imperative that policy-makers and research funding agencies turn their attention to new-onset diabetes in both the young and the old to further our understanding of pathophysiology and inform management of the disease in these growing populations.

Acknowledgements We thank M. Grams, Assistant Professor, Department of Nephrology, Johns Hopkins University, for her insightful comments on a draft version of this commentary.

Duality of interest The authors declare that there is no duality of interest asscociated with this manuscript.

Contribution statement ES was responsible for the conception and the design of the manuscript. Both authors were involved in drafting the article, revising it critically for important intellectual content, and approved the version to be published. 


\section{References}

1. Chen L, Magliano DJ, Zimmet PZ (2012) The worldwide epidemiology of type 2 diabetes mellitus - present and future perspectives. Nat Rev Endocrinol 8:228-236

2. National Center for Health Statistics (2013) Early release of selected estimates based on data from the 2012 National Health Interview Survey: Diagnosed Diabetes. Available from www.cdc.gov/nchs/ nhis/released201306.htm, accessed 13 Sept 2013

3. United Nations (2009) World population ageing: 2009. New York: Department of Economic and Social Affairs. Available from www.un.org/esa/population/publications/WPA2009/WPA2009 WorkingPaper.pdf, accessed 9 Sept 2013

4. Demmer RT, Zuk AM, Rosenbaum M, Desvarieux M (2013) Prevalence of diagnosed and undiagnosed type 2 diabetes mellitus among US adolescents: results from the Continuous NHANES, 1999-2010. Am J Epidemiol 178:1106-1113

5. Ogden CL, Carroll M (2010) Prevalence of obesity among children and adolescents: United States, trends 1963-1965 through 20072008. NCHS Health E-Stat. Available from www.cdc.gov/nchs/ data/hestat/obesity_child_07_08/obesity_child_07_08.htm, accessed 13 Sept 2013

6. Ogden CL, Carroll MD, Kit BK, Flegal KM (2012) Prevalence of obesity and trends in body mass index among US children and adolescents, 1999-2010. JAMA 307:483-490

7. Berkowitz SA, Meigs JB, Wexler DJ (2013) Age at type 2 diabetes onset and glycaemic control: results from the National Health and Nutrition Examination Survey (NHANES) 2005-2010. Diabetologia. doi:10.1007/s00125-013-3036-4

8. American Diabetes Association (2013) Standards of medical care in diabetes-2013. Diabetes Care 36(Suppl 1):S11-S66

9. Diabetes UK (2012). Position statement: early identification of people with, and at high risk of type 2 diabetes and interventions for those at high risk. Available from www.diabetes.org.uk/Documents/ Position\%20statements/diabetes-uk-position-statement-earlyidentification-type-2-0513.pdf, accessed 13 Sept 2013

10. Zhang X, Decker FH, Luo H et al (2010) Trends in the prevalence and comorbidities of diabetes mellitus in nursing home residents in the United States: 1995-2004. J Am Geriatr Soc 58:724-730

11. Pani L, Korenda L, Meigs JB et al (2008) Effect of aging on A1C levels in persons without diabetes: evidence from the Framingham Offspring Study and NHANES 2001-2004. Diabetes Care 31:1991-1996

12. Xiao J, Weng J, Ji L et al (2013) Worse pancreatic beta-cell function and better insulin sensitivity in older Chinese without diabetes. J Gerontol A Biol Sci Med Sci. doi:10.1093/gerona/glt104

13. Gunasekaran U, Gannon M (2011) Type 2 diabetes and the aging pancreatic beta cell. Aging (Albany NY) 3:565-575

14. Knowler WC, Barrett-Connor E, Fowler SE (2002) Reduction in the incidence of type 2 diabetes with lifestyle intervention or metformin. N Engl J Med 346:393-403

15. Crandall J, Barzilai N (2003) Treatment of diabetes mellitus in older people: oral therapy options. J Am Geriatr Soc 51:272-274

16. D'Adamo E, Caprio S (2011) Type 2 diabetes in youth: epidemiology and pathophysiology. Diabetes Care 34(Suppl 2):S161-S165
17. Narayan KMV, Boyle JP, Thompson TJ, Sorensen SW, Williamson DF (2003) Lifetime risk for diabetes mellitus in the United States. JAMA 290:1884-1890

18. Action to Control Cardiovascular Risk in Diabetes Study Group, Gerstein HC, Miller ME et al (2008) Effects of intensive glucose lowering in type 2 diabetes. N Engl J Med 358:2545-2559

19. ACCORD Study Group, Gerstein HC, Miller ME et al (2011) Longterm effects of intensive glucose lowering on cardiovascular outcomes. N Engl J Med 364:818-828

20. Advance Collaborative Group, Patel A, MacMahon S et al (2008) Intensive blood glucose control and vascular outcomes in patients with type 2 diabetes. N Engl J Med 358:2560-2572

21. Duckworth W, Abraira C, Moritz T et al (2009) Glucose control and vascular complications in veterans with type 2 diabetes. $\mathrm{N}$ Engl $\mathrm{J}$ Med 360:129-139

22. Skyler JS, Bergenstal R, Bonow RO et al (2009) Intensive glycemic control and the prevention of cardiovascular events: implications of the ACCORD, ADVANCE, and VA diabetes trials: a position statement of the American Diabetes Association and a scientific statement of the American College of Cardiology Foundation and the American Heart Association. Diabetes Care 32:187-192

23. Inzucchi SE, Bergenstal RM, Buse JB et al (2012) Management of hyperglycaemia in type 2 diabetes: a patient-centered approach: position statement of the American Diabetes Association (ADA) and the European Association for the Study of Diabetes (EASD). Diabetologia 55:1577-1596

24. Buse JB, Ginsberg HN, Bakris GL et al (2007) Primary prevention of cardiovascular diseases in people with diabetes mellitus: a scientific statement from the American Heart Association and the American Diabetes Association. Circulation 115:114-126

25. Liu LL, Yi JP, Beyer J et al (2009) Type 1 and type 2 diabetes in Asian and Pacific Islander U.S. youth: the SEARCH for Diabetes in Youth Study. Diabetes Care 32(Suppl 2):S133-S140

26. Mayer-Davis EJ, Beyer J, Bell RA et al (2009) Diabetes in African American youth: prevalence, incidence, and clinical characteristics: the SEARCH for Diabetes in Youth Study. Diabetes Care 32(Suppl 2):S112-S122

27. Today Study Group, Zeitler P, Hirst K et al (2012) A clinical trial to maintain glycemic control in youth with type 2 diabetes. $\mathrm{N}$ Engl $\mathrm{J}$ Med 366:2247-2256

28. Duncan GE (2006) Prevalence of diabetes and impaired fasting glucose levels among US adolescents: National Health and Nutrition Examination Survey, 1999-2002. Arch Pediatr Adolesc Med 160:523-528

29. Li C, Ford ES, Zhao G, Mokdad AH (2009) Prevalence of prediabetes and its association with clustering of cardiometabolic risk factors and hyperinsulinemia among U.S. adolescents: National Health and Nutrition Examination Survey 2005-2006. Diabetes Care 32:342-347

30. Okosun IS, Seale JP, Boltri JM, Davis-Smith M (2012) Trends and clustering of cardiometabolic risk factors in American adolescents from 1999 to 2008. J Adolesc Health 50:132-139

31. Cali AM, Caprio S (2008) Prediabetes and type 2 diabetes in youth: an emerging epidemic disease? Curr Opin Endocrinol Diabetes Obes $15: 123-127$ 